\title{
Trends in rainfall erosivity in NE Spain at annual, seasonal and daily scales, 1955-2006
}

\author{
M. Angulo-Martínez and S. Beguería \\ Department of Soil and Water, Estación Experimental de Aula Dei-Consejo Superior \\ de Investigaciones Científicas (EEAD-CSIC), 1005 Avda. Montañana, 50080, Zaragoza, Spain
}

Correspondence to: S. Beguería (santiago.begueria@csic.es)

Received: 19 April 2012 - Published in Hydrol. Earth Syst. Sci. Discuss.: 16 May 2012

Revised: 3 September 2012 - Accepted: 15 September 2012 - Published: 10 October 2012

\begin{abstract}
Rainfall erosivity refers to the ability of precipitation to erode soil, and depends on characteristics such as its total volume, duration, and intensity and amount of energy released by raindrops. Despite the relevance of rainfall erosivity for soil degradation prevention, very few studies have addressed its spatial and temporal variability. In this study the time variation of rainfall erosivity in the Ebro Valley (NE Spain) is assessed for the period 1955-2006. The results show a general decrease in annual and seasonal rainfall erosivity, which is explained by a decrease of very intense rainfall events whilst the frequency of moderate and low events increased. This trend is related to prevailing positive conditions of the main atmospheric teleconnection indices affecting the West Mediterranean, i.e. the North Atlantic Oscillation (NAO), the Mediterranean Oscillation (MO) and the Western Mediterranean Oscillation (WeMO).
\end{abstract}

\section{Introduction}

Rainfall erosivity can be defined as the potential of a rainfall event to erode soil, and is a consequence of the interaction of several precipitation characteristics at the event scale. Rainfall erosivity models take into account the continuous and discrete characters of precipitation by considering precipitation amounts and intensities together with the energy released by raindrops when they hit the soil surface. Individual raindrop impacts are able to detach the soil aggregates and strike them up into the air as rain splash, preparing them for being transported by sheet wash or other processes and causing a diffusive displacement of particles down the slope if the topography is not perfectly flat. Rain splash is also able to disrupt the soil aggregates, and the redistribution of soil particles blocks the soil pores, causing crusting and reduced infiltration. Infiltration, saturation and excessive overland flow may occur as a consequence of the amount and intensity of precipitation over short time periods, causing sheet and concentrated flow with high potential for detaching and transporting soil particles.

The study of rainfall erosivity is thus highly relevant for soil degradation mitigation. Despite its applied relevance, the climatology of rainfall erosivity (i.e. its interannual and seasonal variation, spatial patterns, etc.) is surprisingly the topic of very few studies. In the context of climate change, a relevant question is whether or not long-term trends can be detected over the last decades that may help confirm the projections made by global climate models. The Mediterranean basin is one of the areas of the world where current climate projections suggest the highest changes in precipitation (Sauerborn et al., 1999; Kendon et al., 2010; Beaulant et al., 2011; Tramblay et al., 2012). It is expected that the annual precipitation will decrease in the Mediterranean, while higher amounts of erosive rainfall can also be expected as a consequence of changes in precipitation variability and precipitation extremes.

A number of studies found decreasing annual precipitation in the Iberian Peninsula (IP) since the mid 20th century, with seasonal and spatial differences (Rodríguez-Puebla et al., 1998; Esteban-Parra et al., 1998; Paredes et al., 2006; López-Bustinset al., 2008; González-Hidalgo et al., 2009, 2010; Rodrigo, 2010; López-Moreno et al., 2010). These trends have been related to changes towards dryer conditions due to a northward displacement of the polar fronts, and are consistent with the evolution of major teleconnection 
patterns affecting precipitation over the IP, such as the North Atlantic Oscillation (NAO), the Mediterranean Oscillation (MO) and the Western Mediterranean Oscillation (WEMO).

Very few studies have analyzed trends in rainfall erosivity. Meusburgeret al. (2012) analyzed the spatio-temporal variability of rainfall erosivity in Switzerland and found an increasing trend from May to October. Focusing on the Mediterranean side of the IP, de Luis et al. (2010a) found an overall decrease in annual rainfall and increases in rainfall concentration, while changes in rainfall erosivity varied in space. Their analysis was based on the Modified Fournier Index (MFI, Arnoldus, 1977) with monthly precipitation data. This is an important concern, since rainfall erosivity depends largely on a few number of short but very intense rain episodes that are largely smoothed when data is aggregated at coarser time resolutions.

The USLE/RUSLE $R$ factor (Wischmeier, 1959; Wischmeier and Smith, 1978; Brown and Foster, 1987; Renard et al., 1997) is probably the most widely used rainfall erosivity index. It is defined as the mean value of the annual cumulative $\mathrm{EI}_{30}$ index. TheEI 30 index $\left(\mathrm{MJ} \mathrm{mm} \mathrm{ha}^{-1} \mathrm{~h}^{-1}\right)$ is obtained for each rainfall event as the product of the kinetic energy of the rain $(E)$ and the maximum intensity recorded in $30 \mathrm{~min}$. Its calculation requires high frequency rainfall data - typically one data every 15 min or less - or pluviograph records. In addition, reliable values of the $R$ factor can only be obtained from long data series spanning over several decades. Such conditions are very often not met, so a number of studies have been devoted to estimating rainfall erosivity from coarser data such as highly available daily rainfall time series (Richardson et al., 1983; Bagarello and D' Asaro, 1994; Petkovsek and Mikos, 2004; Angulo-Martínez and Beguería, 2009; Meusburger et al., 2012). Such relationships allow undertaking climatological studies of rainfall erosivity with dense and long datasets. In this article we use an estimation of the $\mathrm{EI}_{30}$ index based on daily rainfall intensities for assessing the temporal variation of rainfall erosivity in the NE quadrant of the IP at the annual, monthly and daily time scales.

\section{Study area and methods}

\subsection{Study area}

The study area is located at NE of Spain, with an area of about $85000 \mathrm{~km}^{2}$ that corresponds to the Ebro River basin (Fig. 1). The area limits to the north with the Cantabric Sea (Atlantic Ocean), the Cantabrian Range and the Pyrenees. Maximum elevations are above $3000 \mathrm{~m}$ a.s.l. At the $\mathrm{S}$ and SW the Iberian Range closes the Ebro basin, with maximum elevations in the range of 2000-2300 ma.s.l. Catalan Prelitoral Range, with maximum elevations of 1000$1900 \mathrm{~m}$ a.s.l., limits the valley to the $\mathrm{E}$, and then continues to the Mediterranean Sea. It is a topographical complex area

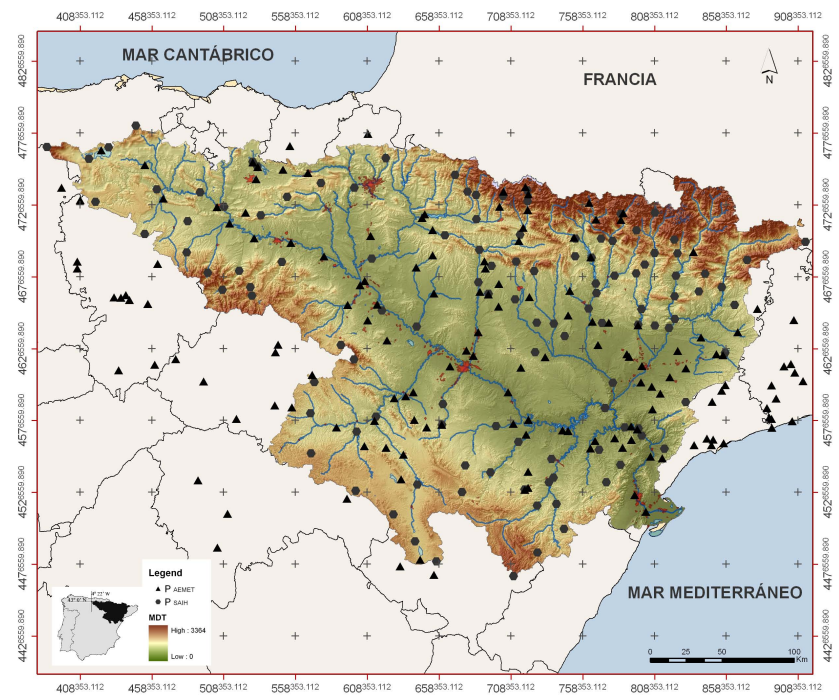

Fig. 1. Digital Terrain Model of the study area showing the spatial distribution of the rainfall gauges used in the study (UTM coordinates). $P_{\text {AEMET }}$ indicates daily rainfall data series for period $1955-$ 2006 provided by the Spanish Meteorological Agency. $P_{\text {SAIH }}$ indicates the 15' rainfall data series for period 1997-2006 provided by the Automatic Hydrologic Information System of the Ebro river basin.

where mountain areas represent approximately $20 \%$ of the study area.

Climate is influenced by the Atlantic Ocean and the Mediterranean Sea, determining a NW-SE climatic gradient. The central area has continental climate with semi-arid conditions as a consequence of the isolation from the oceanic influence due to topographical shading (Lana and Burgueño, 1998). Precipitation is characterized by alternating wet and dry periods as a consequence of the seasonal displacement of the polar front and its associated pressure systems. Drought situations can be followed by torrential rainfall events. Precipitation variability is the main characteristic, inter and intra annually. These properties increase towards the SE and in the center. The most extreme precipitation events are usually recorded along the Mediterranean seaside (Romero et al., 1998; Peñarrocha et al., 2002).

As is true for the rest of climatic variables, rainfall erosivity is characterized by a transition from the NW to the SE (Fig. 2). Three main areas can be recognized: (i) the northwest is influenced by the Atlantic Ocean and shows the highest monthly rainfall precipitation with minimum rainfall erosivity, and the highest erosivity is attained coinciding with late spring storms; (ii) the central area shows lower precipitation amounts, though erosivity is greater and has two peaks in May-June and August-September; and (iii) the SE zone has a typical Mediterranean rainfall regime with maxima in spring and autumn, and has the highest erosivities of the study area, especially in autumn. 


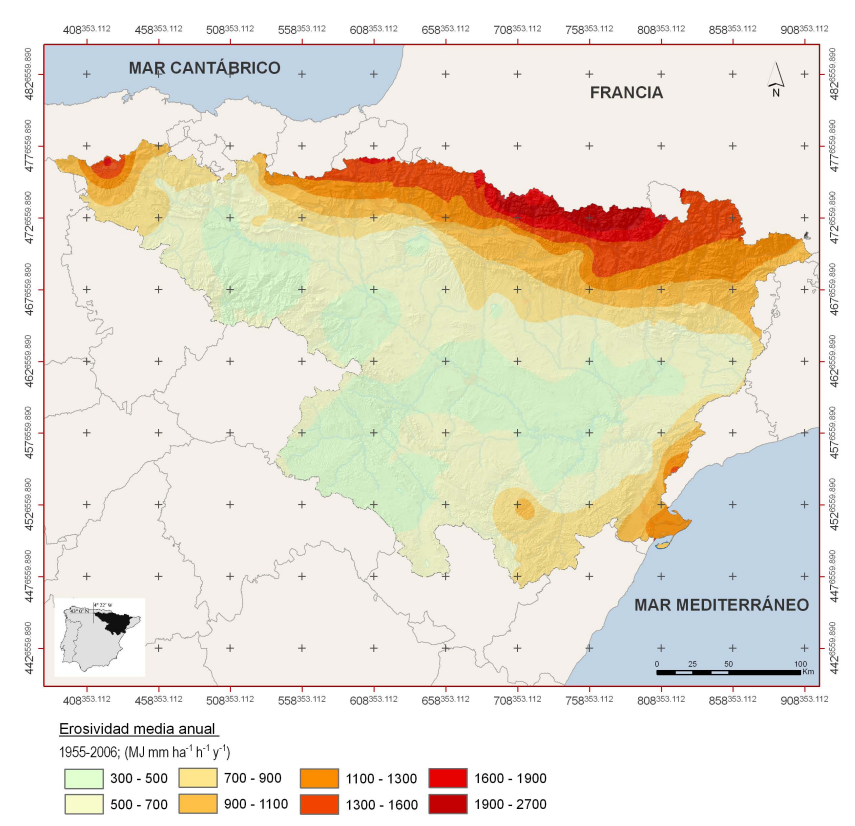

Fig. 2. Mean annual rainfall erosivity during the period 1955-2006 (MJ mm ha ${ }^{-1} \mathrm{~h}^{-1} \mathrm{yr}^{-1}$ ).

The main land use in terms of surface is agriculture (representing approximately $46 \%$ of the area). It is extended around the Ebro Valley occupying a broader area close to the Mediterranean coast. Traditionally, agricultural soils remain uncovered in most cases during autumn and early winter, and as a consequence rainfall erosivity is the main cause of soil erosion during that period.

\subsection{Daily rainfall erosivity database}

For this study two databases were used (Fig. 1): (i) 110 rainfall series from the Ebro river basin authority's hydrologic information system (SAIH Ebro), with a time resolution of 15 min since $1997\left(P_{\mathrm{SAIH}}\right)$; and (ii) 156 daily rainfall series from the Spanish meteorological agency (AEMET) with daily (06:00 to $06: 00 \mathrm{~h})$ precipitation amounts for the period 1955-2006 $\left(P_{\text {AEMET }}\right)$. Precipitation time series were pre-processed with techniques that included reconstruction, gap filling, quality control and homogeneity testing (VicenteSerrano et al., 2009a). The SAIH dataset had the adequate time resolution for computing rainfall erosivity, but only covered eleven years. The AEMET dataset had the adequate length for undertaking climatological studies, but its coarser time resolution did not allow direct computation of the $\mathrm{EI}_{30}$ index. Therefore, we used a statistical procedure between the two datasets for obtaining series of daily rainfall erosivity for the period 1955-2006. The process is explained at length in Angulo-Martínez and Beguería (2009), and a summary is provided as Supplement.

Additionally, time series of three widely known teleconnection indices (the North Atlantic Oscillation, NAO; the
Mediterranean Oscillation, MO; and the West Mediterranean Oscialltion, WEMO) were used in order to explore atmospheric explanations for the time evolution of rainfall erosivity. A detailed explanation of the elaboration of these time series is provided in Angulo-Martínez and Beguería (2012).

\subsection{Trend analysis}

Annual and seasonal time series were obtained by adding the daily erosivity values at the appropriate aggregation periods. Natural years (from 1 January to 31 December) were used for the annual series, and the usual convention (winter $=$ December to February, spring $=$ March to May, summer $=$ June to August, autumn $=$ September to November) was used for the seasonal series. In addition, time series of the number of daily erosivity events within the limits of the quintiles of each series $(\mathrm{Q} 1=$ below the 20th percentile, $\mathrm{Q} 2=$ between the 20th and 40th percentile, $\mathrm{Q} 3=$ between the 40th and 60th percentile, Q4 = between the 60th and 80th percentile, Q5 = above the 80th percentile) were computed and aggregated at the annual and seasonal time scales.

The Mann-Kendall test for monotonic trends was used for identifying time trends on those series (Mann, 1945). A block bootstrap procedure was used for obtaining improved significance test when working with time series data (Künsch, 1989). The functions tsboot from the $R$ boot library and MannKendall from the $R$ Kendall library were used to perform the analyses. Maps showing the location of the significant series were then produced to help identify possible spatial patterns.

The per-decade change of the annual and seasonal erosivity and the number of events in the first (Q1) and fifth (Q5) quintiles was also represented in the maps to help visualize the sign and magnitude of erosivity trends. Per-decade change was estimated for each series by means of ordinary least squares (OLS) regression upon time, and surface maps were generated by means of local first grade polynomial interpolation.

Relationships between time variation of rainfall erosivity and the three teleconnection indices (NAO, MO and WEMO) were explored by means of the Pearson's correlation test. The number of significantly correlated series was computed for the annual and seasonal erosivity series and for the number of events in the first and fifth quintile. Significance was evaluated at $\alpha=0.05$ confidence level, so on average a number of $n=7.8$ false positives could be expected from the 156 time series sample.

\section{Results}

\subsection{Annual and seasonal rainfall erosivity}

The annual rainfall erosivity experienced decreasing trends in most of the study area (Fig. 3). Per-decade change was as high as $-200 \mathrm{MJ} \mathrm{mm} \mathrm{ha}^{-1} \mathrm{~h}^{-1} \mathrm{yr}^{-1}$ in some areas, such as 


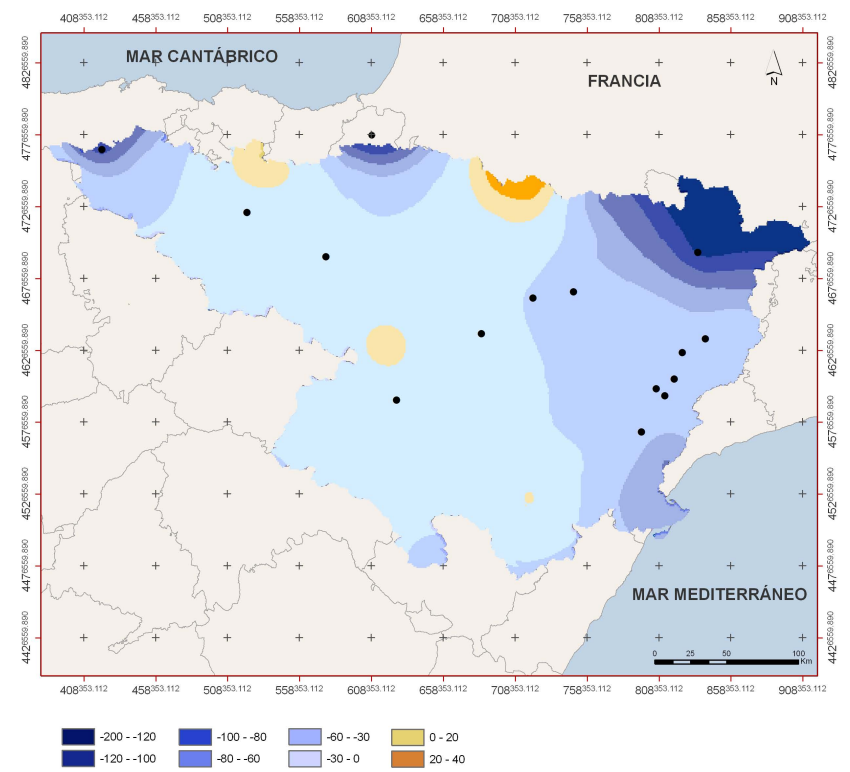

Fig. 3. Per decade change of annual rainfall erosivity during the period 1955-2006 (MJ mm ha $\left.{ }^{-1} \mathrm{~h}^{-1} \mathrm{y}^{-1}\right)$. Black circles indicate data series for which the trend was significant at the $\alpha=0.05$ confidence level.

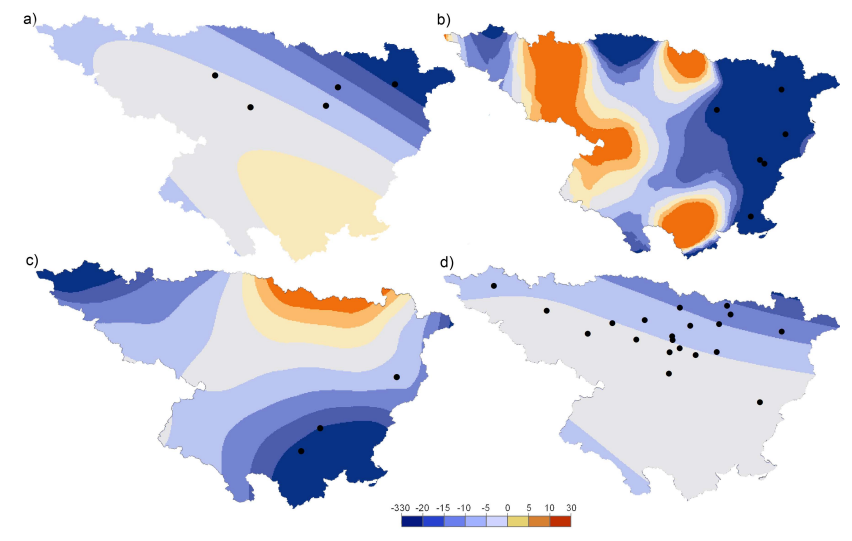

Fig. 4. Per decade change of seasonal rainfall erosivity during the period 1955-2006 (MJ mm ha $\left.{ }^{-1} \mathrm{~h}^{-1} \mathrm{y}^{-1}\right)$ : (a) DJF, (b) MAM, (c) JJA, (d) SON. Black circles indicate data series for which the trend was significant at the $\alpha=0.05$ confidence level.

in the NE of the study area (eastern Pyrenees), but in most of the area it was lower than $30 \mathrm{MJ} \mathrm{mm} \mathrm{ha}^{-1} \mathrm{~h}^{-1} \mathrm{yr}^{-1}$ per decade. When compared to the mean annual rainfall erosivity (Fig. 2), the highest relative changes occurred at the NE of the study area were they represented $60-80 \%$ of the average over the whole study period (five decades).

Spatial differences were most noticeable when analysed at a seasonal basis (Fig. 4). While in winter and spring trends were negative in most of the study area, with the most negative trends in the NE corner, in summer and autumn there were larger spatial differences. Summer yielded the most heterogeneous results, since in some interior areas slightly
Table 1. Number and proportion of series with significant trends, significance level $\alpha=0.05$.

\begin{tabular}{lrr}
\hline $\begin{array}{l}\text { Time } \\
\text { period }\end{array}$ & $\begin{array}{r}\text { No positive } \\
\text { trends }(\%)\end{array}$ & $\begin{array}{r}\text { No negative } \\
\text { trends }(\%)\end{array}$ \\
\hline Annual & $1(0.6 \%)$ & $23(14.7 \%)$ \\
Spring & $1(0.6 \%)$ & $8(5.1 \%)$ \\
Summer & 0 & $9(5.8 \%)$ \\
Autumn & $1(0.6 \%)$ & $3(1.9 \%)$ \\
Winter & 0 & $25(16.0 \%)$ \\
\hline
\end{tabular}

positive trends were registered, while the NE quadrant and some smaller areas in the $\mathrm{N}$ and $\mathrm{NW}$ experienced strong negative trends. In autumn negative trends predominated overall and were especially strong in the SE and NW corners, but positive trends were also found in the $\mathrm{N}$ along the Pyrenean range. Although negative trends predominated overall at both annual and seasonal basis, these results should be taken with care since significance was achieved only in a small fraction of the stations (Table 1).

\subsection{Daily rainfall erosivity}

Variation in the number of daily events grouped by quintiles allowed assessing trends in the occurrence of rainfall erosivity events across the range of erosivity values (Fig. 5). Since the range of the quintiles were calculated considering the whole study period (1955-2006), negative values indicate a diminishing number of events, while positive values indicate an increasing number of events. The results show that the number of very low and low erosivity events $(\mathrm{Q} 1$, below $20 \%$, and Q2, between 20 and $40 \%$ ) increased in a large number of stations, while the number of medium, high and very high erosivity events (Q3 to Q5) decreased. Spatially, the number of events in the first quintile increased between one and four events per year in most of the study area, and only in the NE corner (eastern Pyrenees) was a negative trend found (Fig. 6). Trends were significant in the majority of stations $(55.8 \%)$. The number of events in the fifth quintile, on the other hand, decreased between 0.25 and one event per year, with significant trends in $21.8 \%$ of the stations.

The same pattern (increasing number of Q1 events and decreasing number of Q5 events) was found at the seasonal basis (Figs. 7 and 8), with a few exceptions: (i) the number of Q1 events decreased in winter in the NE corner; and (ii) the number of Q5 events increased in autumn in a small area in the central and western Pyrenees at the $\mathrm{N}$ of the study area. The number and proportion of stations with significant trends are shown in Tables 2 and 3.

\subsection{Teleconnection patterns}

The time evolution of the three teleconnection indices is shown in Fig. 9. A tendency towards a prevalence of positive 


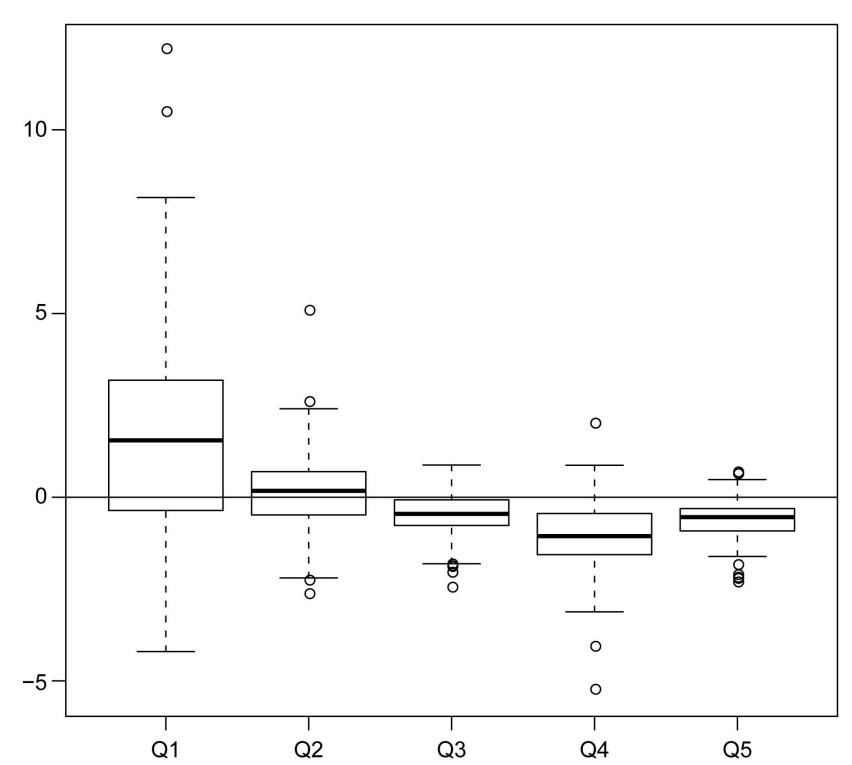

Fig. 5. Boxplots of trends with the number of daily rainfall erosivity events classified by quintiles of daily erosivity over the whole period 1955-2006.

Table 2. Number and proportion of series with trends in the number of events in the first quintile (Q1), significance level $\alpha=0.05$.

\begin{tabular}{lrr}
\hline $\begin{array}{l}\text { Time } \\
\text { period }\end{array}$ & $\begin{array}{r}\text { No positive } \\
\text { trends }(\%)\end{array}$ & $\begin{array}{r}\text { No negative } \\
\text { trends }(\%)\end{array}$ \\
\hline Annual & $72(46.2 \%)$ & $15(9.6 \%)$ \\
Spring & $59(37.8 \%)$ & $11(7.1 \%)$ \\
Summer & $54(34.6 \%)$ & $11(7.1 \%)$ \\
Autumn & $81(51.9 \%)$ & $7(4.5 \%)$ \\
Winter & $54(34.6 \%)$ & $15(9.6 \%)$ \\
\hline
\end{tabular}

values is clear in the case of the NAO and the MO. Correlations between the time evolution of rainfall erosivity and the teleconnections (Table 4) revealed a high influence of NAO on winter erosivity (43\% of the series positively correlated) and autumn (31\%), while WEMO and MO had lower influence. With respect to the number of events in the two extreme quintiles, NAO was again the teleconnection with the highest impact, most especially on the evolution of Q5 in winter (44\% of positively correlated series).

\section{Discussion}

Planning of soil conservation measurements, especially concerning agriculture, requires a good knowledge of all factors affecting soil erosion. Among them, rainfall erosivity is one of the least studied, although its spatial and temporal dynamics can be of paramount importance when they are related to other factors such as land use and cropping practices. The development of long time series of daily rainfall

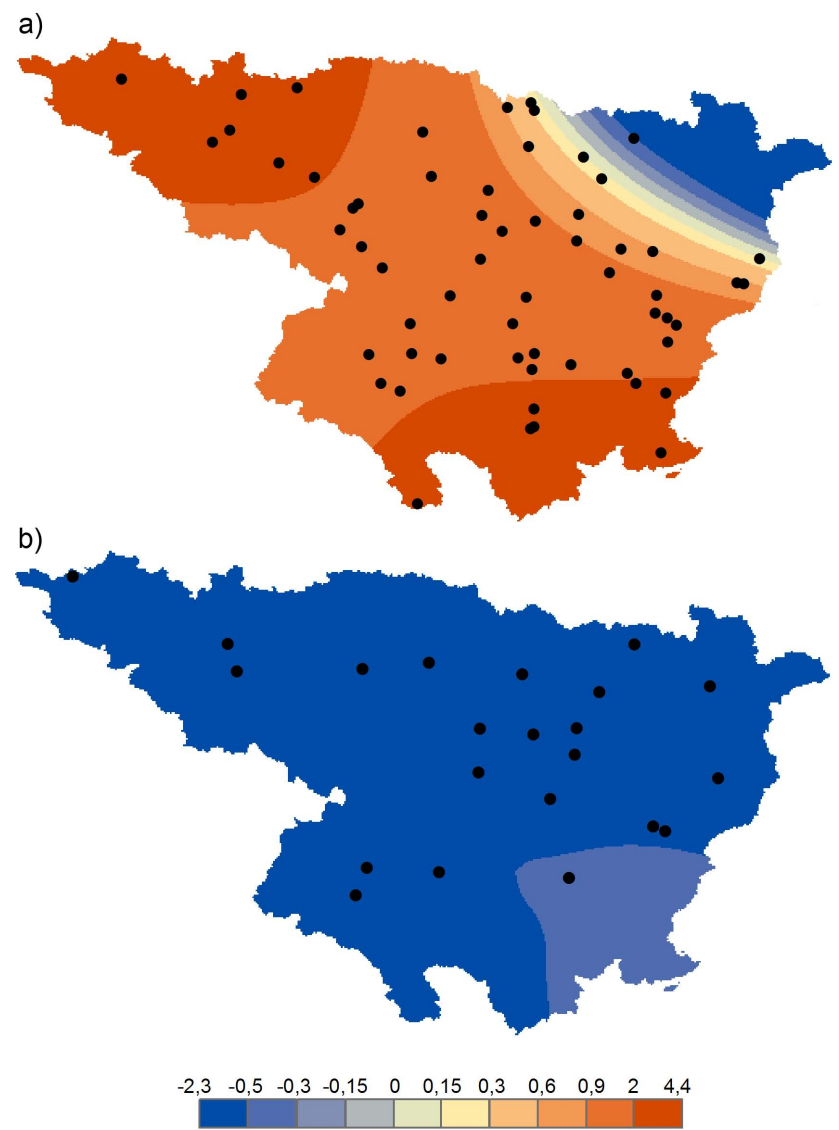

Fig. 6. Per decade change in the number of daily rainfall erosivity events corresponding to (a) the first (Q1) and (b) fifth (Q5) quintiles at the annual scale for the period 1955-2006. Black circles indicate significant trends at the $\alpha=0.05$ confidence level.

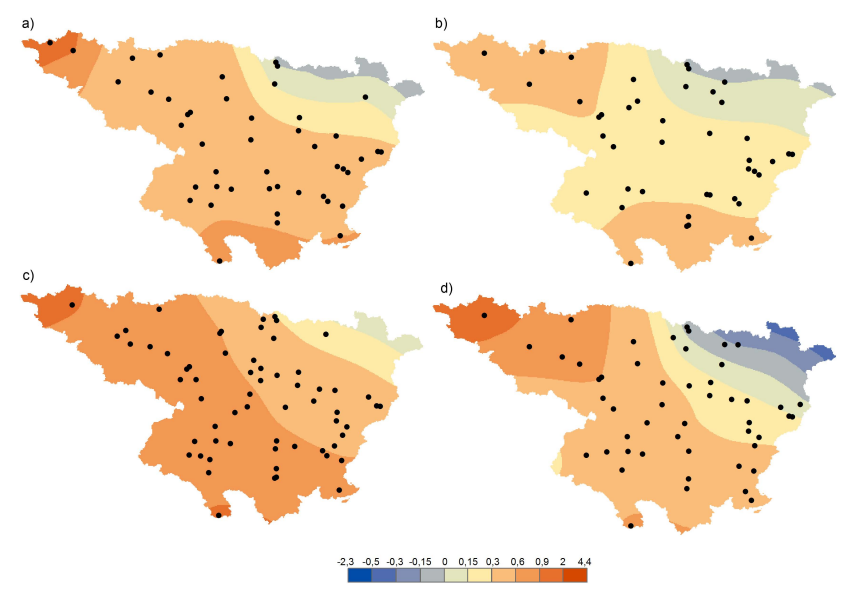

Fig. 7. Per decade change in the number of daily rainfall erosivity events corresponding to the first (Q1) quintile at the seasonal scale for the period 1955-2006: (a) DJF, (b) MAM, (c) JJA, (d) SON. Black circles indicate significant trends at the $\alpha=0.05$ confidence level. 


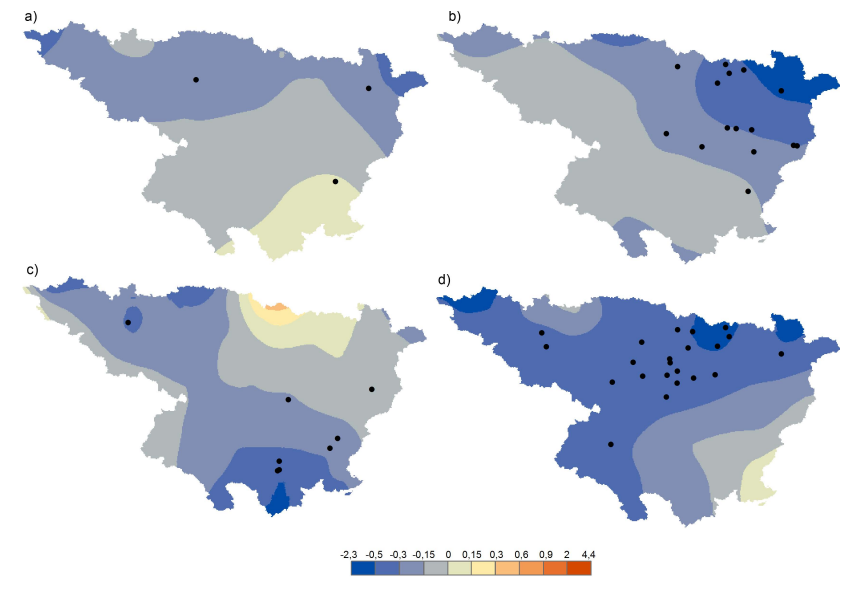

Fig. 8. Per decade change in the number of daily rainfall erosivity events corresponding to the fifth (Q5) quintile at the seasonal scale for the period 1955-2006: (a) DJF, (b) MAM, (c) JJA, (d) SON. Black circles indicate significant trends at the $\alpha=0.05$ confidence level.
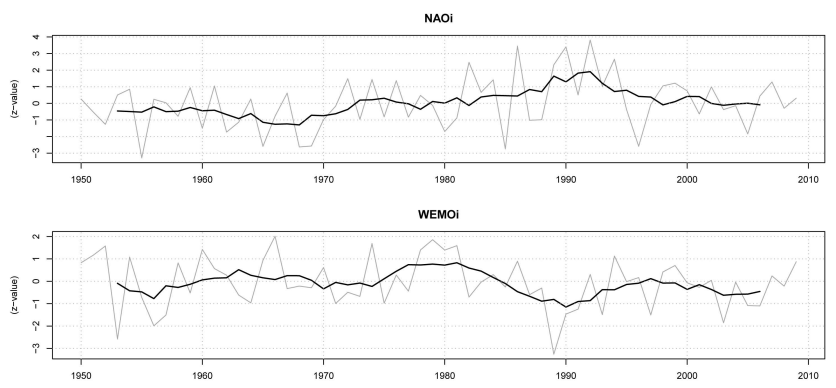

MOi

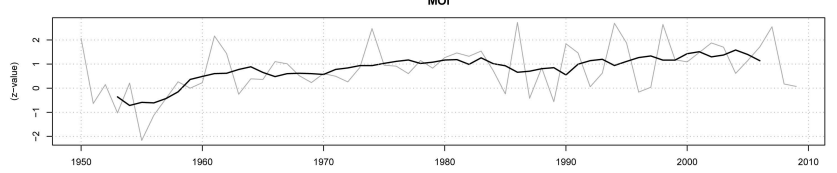

Fig. 9. Temporal evolution of October to March NAO, WeMO and MO indices obtained from average daily indices (thin black line) and 5-yr running average (thick grey line).

erosivity, even subject to uncertainty, can be of great value in assessing the spatial and temporal dynamics of rainfall erosivity. Compared to these, data at coarser temporal resolution such as monthly precipitation may miss the importance of a few, very intense events that account for a large fraction of the annual or seasonal rainfall erosivity amounts. Our results show decreasing rainfall erosivities at the annual and seasonal scales over most of the area. This could be explained in part by negative trends in total precipitation amounts over the IP, especially during the wet season from October to May (Rodríguez-Puebla et al., 1998; Esteban-Parra et al., 1998; Paredes et al., 2006; López-Bustins et al., 2008; GonzálezHidalgo et al., 2009, 2010; Rodrigo, 2010; López-Moreno et al., 2010). However, deeper inspection revealed that this trend in the annual erosivity was related to changes in the
Table 3. Number and proportion of series with trends in the number of events in the fifth quintile (Q5), significance level $\alpha=0.05$.

\begin{tabular}{lrr}
\hline $\begin{array}{l}\text { Time } \\
\text { period }\end{array}$ & $\begin{array}{r}\text { No positive } \\
\text { trends }(\%)\end{array}$ & $\begin{array}{r}\text { No negative } \\
\text { trends }(\%)\end{array}$ \\
\hline Annual & 0 & $34(21.8 \%)$ \\
Spring & $1(0.6 \%)$ & $6(3.9 \%)$ \\
Summer & 0 & $23(14.7 \%)$ \\
Autumn & $1(0.6 \%)$ & $9(5.8 \%)$ \\
Winter & 0 & $28(21.8 \%)$ \\
\hline
\end{tabular}

frequency distribution of erosivity events, since the number of events of low erosivity increased while the number of highly erosive events decreased. Due to the exponential distribution of rainfall erosivity, the higher events account for a large part of the total cumulative erosivity, so even a small reduction in the frequency of high events is able to produce a large reduction of the annual or seasonal erosivity. These results are in agreement with previous studies. In their analysis of daily precipitation in the NE of Iberia, López-Moreno et al. (2010) found decreasing trends in the number of heavy precipitation events and in the relative contribution of heavy events to the annual rainfall, while the number and relative importance of light and moderate events increased. Similarly, Martínez et al. (2007) described increasing contribution of light and moderate events to total precipitation amounts, and Rodrigo and Trigo (2007) found global decrease in precipitation intensity over the IP. Recent results based on the nonstationary peaks-over-threshold approach to extreme events analysis found evidences of decreasing frequency and magnitude of extreme rainfall events over most of the IP and in particular in its NE quadrant (Beguería et al., 2011; Acero et al., 2012).

Based on monthly precipitation data covering the Mediterranean basins of the IP, de Luis et al. (2010a) reported a generalized decrease of the Modified Fourier Index (MFI). In the Ebro basin, coinciding with the study area of this study, they found that decreasing trends of the MFI predominated in general, except at the $\mathrm{N}$ of the study area (Pyrenees). They did not perform seasonal analysis, but in another study the same authors found that annual and monthly precipitation generally decreased in the Ebro basin, except in February and October when a slightly increase was found along the Pyrenees (González-Hidalgo et al., 2009, 2010; de Luis et al., 2010b). This coincides with our findings, since the frequency of high erosivity events (Q5) only increased in autumn in the Pyrenees.

Our results and those of the cited authors contrast with studies for the whole Mediterranean basin, for which a general increase of precipitation intensity has been described (Brunetti et al., 2001; Norrant and Douguédroit, 2006; Goodess and Jones, 2002). However, correlation analysis revealed links with teleconnection patterns that help explain 
Table 4. Number of significant correlations between atmospheric circulation indices and rainfall erosivity (Pearson's correlation test, significance level $\alpha=0.05$ ).

\begin{tabular}{rrrrrr}
\hline \multicolumn{7}{c}{ Annual } & DJF & MAM & JJA & SON \\
\hline \multicolumn{7}{c}{ Erosivity (EI) } \\
\hline $\mathrm{NAO}_{i}$ & $13(8.3 \%)$ & $67(43 \%)$ & 0 & $6(3.9 \%)$ & $49(31.4 \%)$ \\
$\mathrm{WEMO}_{i}$ & $8(5.1 \%)$ & $20(12.8 \%)$ & $3(1.9 \%)$ & $1(0.6 \%)$ & $10(6.4 \%)$ \\
$\mathrm{MO}_{i}$ & $13(8.3 \%)$ & $7(4.5 \%)$ & $2(1.9 \%)$ & $27(17.3 \%)$ & $8(5.1 \%)$ \\
\hline \multicolumn{7}{c}{ No. of daily erosivity events in the first quintile (Q1) } \\
\hline $\mathrm{NAO}_{i}$ & $18(11.5 \%)$ & $23(14.7 \%)$ & $17(11 \%)$ & $11(7.1 \%)$ & $25(16 \%)$ \\
$\mathrm{MO}_{i}$ & $10(6.4 \%)$ & $12(8 \%)$ & $10(6.4 \%)$ & $8(5.1 \%)$ & $11(7.1 \%)$ \\
\hline \multicolumn{7}{c}{ No. of daily erosivity events in the fifth quintile (Q5) } \\
$\mathrm{NAO}_{i}$ & $2(1.9 \%)$ & $68(44 \%)$ & $2(1.9 \%)$ & $3(1.9 \%)$ & $39(25 \%)$ \\
$\mathrm{WEMO}_{i}$ & $19(12.2 \%)$ & $20(12.8 \%)$ & $3(1.9 \%)$ & $4(2.6 \%)$ & $11(7.1 \%)$ \\
$\mathrm{MO}_{i}$ & $20(12.8 \%)$ & $15(9.6 \%)$ & $4(2.6 \%)$ & $29(18.6 \%)$ & $3(1.9 \%)$ \\
\hline \multicolumn{7}{c}{$9(5.8 \%)$} & $7(4.5 \%)$ & $28(18 \%)$ \\
\hline
\end{tabular}

the negative trend in intense precipitation observed in the instrumental records. As other authors have pointed out, strong precipitation events in the study area are significantly related to negative phases of the NAO, MO and WEMO (GonzálezHidalgo et al., 2009). The generalized decreasing precipitation along the Mediterranean basin of the IP has been related to prevailing positive conditions of NAO and MO. AnguloMartínez and Beguería (2012) found a significant relationship between rainfall erosivity and these indices, which was largest for MO and WEMO. These authors related the positive trend of these indices with the observed reduction in the occurrence of extreme rainfall events. Similar results were obtained by Vicente-Serrano et al. (2009b) with respect to extreme precipitation in NE Spain. Here we found that a high number of rainfall erosivity series were correlated with the NAO, most notably in winter and autumn, and that the reduction in the number of erosivity events in the fifth quintile was also related to the time evolution of the NAO.

\section{Conclusions}

Analysis of the temporal evolution of rainfall erosivity revealed generalized decreasingtrends at the annual and monthly scales during the period 1955-2006. This coincided with a decrease in the number of highly erosive events and with increasing number of low erosivity events at the daily scale. Negative trends were also found by other authors analyzing extreme precipitation on the Iberian Peninsula, contrasting with broader studies indicating positive trends in extreme precipitation at the global and regional (Mediterranean basin) scales. In the context of the Iberian Peninsula, negative trends can be explained by a relative displacement of the polar fronts northwards, revealed by the intensification (positive trend) of the North Atlantic Oscillation and the
Mediterranean Oscillation. As it has been pointed out by several authors before, positive NAO and MO are related with a fewer number (and with lower magnitude) of rainfall events in the region.

This study reveals that rainfall erosivity is characterized by complex patterns in time and space, but their study can be undertaken based on relatively common data (longtime series of daily precipitation and shorter time series of high frequency precipitation). This encourages the climatological study of this rainfall property, given the implications for soil erosion and the hydrological behavior on natural and managed landscapes.

\section{Supplementary material related to this article is available online at: http://www.hydrol-earth-syst-sci.net/ 16/3551/2012/hess-16-3551-2012-supplement.pdf.}

Acknowledgements. We want to express our gratitude to the Spanish Meteorological Agency (Agencia Española de Meteorología, AEMET) and the Ebro Basin Water Authority (ConfederaciónHidrográfica del Ebro, $\mathrm{CHE}$ ) for providing the data used in this study. We also thank two anonymous reviewers for a fruitful discussion that led to improving the original manuscript. This work has been supported by research projects CGL201124185 financed by the Spanish Ministry of Science and Innovation (CICYT) and the European Regional Development Fund (ERDFFEDER), 2010 CZ0021 financed by the Spanish National Research Council (Consejo Superior de Investigaciones Científicas-CSIC) and the Czech Academy of Sciences, and "Grupo de Investigación E68: Geomorfología y Cambio Global" financed by the Aragón Government and the European Social Fund (ESF-FSE). Research of M. A.-M. was supported by a JAE-Predoc grant from the Spanish National Research Council (Consejo Superior de Investigaciones Científicas-CSIC).

Edited by: M. Mikos 


\section{References}

Acero, J. L., García, J. A., and Gallego, M. C.: Peaks-overThreshold Study of Trends in Extreme Rainfall over the Iberian Peninsula, J. Climate, 24, 1089-1105, 2012.

Angulo-Martínez, M. and Beguería, S.: Estimating rainfall erosivity from daily rainfall records: A comparison among methods using data from the Ebro Basin (NE Spain), J. Hydrol., 379, 111-121, 2009.

Angulo-Martínez, M. and Beguería, S.: Evaluation of the Relationship Between the NAO and Rainfall Erosivity in NE Spain During the Period 1955-2006, Adv. Global Change Res., 46, 183197, 2011.

Angulo-Martínez, M. and Beguería, S.: Do atmospheric teleconnection patterns influence rainfall erosivity? A comparison between NAO, MO and WEMO in NE Spain, 1955-2006, J. Hydrol., 450-451, 168-179, doi:10.1016/j.jhydrol.2012.04.063, 2012.

Arnoldus, H. M. J.: Methodology used to determine the maximum potential average annual soil loss due to sheet and rill erosion in Morocco, FAO Soils Bull., 34, 39-51, 1977.

Bagarello, V. and D'Asaro, F.: Estimating single storm erosion index, T. ASAE, 37, 785-791, 1994.

Beaulant, A. L., Joly, B., Nuissier, O., Somot, S., Ducrocq, V., Joly A., Sevault, F., Deque, M., and Ricard, D.: Statistico-dynamical downscaling for Mediterranean heavy precipitation, J. Roy. Meteor. Soc., 137, 736-748, 2011.

Beguería, S., Angulo-Martínez, M., Vicente-Serrano, S. M., LópezMoreno, J. I., and El-Kenawy, A.: Assessing trends in extreme precipitation events intensity and magnitude using nonstationary peaks-over-threshold analysis: a case study in northeast Spain from 1930 to 2006, Int. J. Climatol., 31, 2102-2114, 2011.

Brown, L. C. and Foster, G. R.: Storm erosivity using idealized intensity distributions, T. ASAE, 30, 379-386, 1987.

Brunetti, M., Maugeri, M., and Nanni, T.: Changes in total precipitation,rainy days and extreme events in northeastern Italy, Int. J. Climatol., 21, 861-871, 2001.

de Luis, M., González-Hidalgo, J. C., and Longares, L. A.: Is rainfall erosivity increasing in the Mediterranean Iberian Peninsula?, Land DegradDev, 21, 139-144, 2010a.

de Luis, M., Brunetti, M., González-Hidalgo, J. C., Longares, L. A., and Martín-Vide, L. A.: Changes in seasonal precipitation in the Iberian Peninsula during 1946-2005, Global Planet. Change, 74, 27-33, 2010b.

Esteban-Parra, M. J., Rodrigo, F. S., and Castro-Díez, Y.: Spatial and temporal patterns of rainfall in Spain for the period 18801992, Int. J. Climatol., 18, 1557-1574, 1998.

González-Hidalgo, J. C., Brunetti, M., and de Luis, M.: Precipitation trends in Spanish hydrological divisions, 1946-2005, Clim. Res., 43, 215-228, 2010.

González-Hidalgo, J. C., Lopez-Bustins, J. A., Štepánek, P., MartínVide, J., and de Luis, M.: Monthly rainfall trends on the Mediterranean fringe of the Iberian peninsula during the second-half of the twentieth century (1951-2000), Int. J. Climatol., 29, 14151429, 2009.

Goodess, C. M. and Jones, P. D.: Links between circulation and changesin the characteristics of Iberian rainfall, Int. J. Climatol., 22, 1593-1615, 2002.
Kendon, E. J., Rowell, D. P., and Jones, R. G.: Mechanisms and reliability of future projected changes in daily rainfall, Clim. Dynam., 35, 489-509, 2010.

Künsch, H. R.: The jacknife and the bootstrap for general stationary observations, Ann. Stat., 17, 1217-1241, 1989.

Lana, X., and Burgueño, A.: Spatial and temporal characterization of annual extreme droughts in Catalonia (Northeast Spain), Int. J. Climatol., 18, 93-110, 1998.

Lopez-Bustins, J. A., Martin-Vide, J., and Sanchez-Lorenzo, A.: Iberia winter rainfall trends based upon changes in teleconnection and circulation patterns, Global Planet. Change, 63, 171176, 2008.

López-Moreno, J. I., Vicente-Serrano, S. M., Angulo-Martínez, M., Beguería, S., and El-Kenawy, A.: Trends in daily precipitation on the north eastern Iberian Peninsula, 1955-2006, Int. J. Climatol., 30, 1026-1041, 2010.

Mann, H. B.: Nonparametrictestsagainsttrend.Econometrica, 13, 245-259, 1945.

Martínez, M. D., Lana, X., Burgueño, A., and Serra, C.: Spatial andtemporal daily rainfall regime in Catalonia (NE Spain) derived fromfour precipitation indices, years 1950-2000, Int. J. Climatol., 27, 1527-1632, 2007.

Meusburger, K., Steel, A., Panagos, P., Montanarella, L., and Alewell, C.: Spatial and temporal variability of rainfall erosivity factor for Switzerland, Hydrol. Earth Syst. Sci., 16, 167-177, doi:10.5194/hess-16-167-2012, 2012.

Norrant, C. and Douguédroit, A.: Monthly and daily precipitationtrends in the Mediterranean (1950-2000), Theor. Appl. Climatol., 83, 89-106, 2006.

Paredes, D., Trigo, R. M., García-Herrera, R., and Franco-Trigo, I.: Understanding rainfall changes in Iberia in early spring: weather typing and storm-tracking approaches, J. Hydrometer., 7, 101113, 2006.

Peñarrocha, D., Estrela, M. J., and Millán, M.: Classification of daily rainfall patterns in a Mediterranean area with extreme intensity levels: the Valencia region, Int. J. Climatol., 22, 677-695, 2002.

Petkovsek, G. and Mikos, M.: Estimating the R factor from daily rainfall data in the sub-Mediterranean climate of southwest Slovenia, Hydrolog. Sci. J., 49, 869-877, 2004.

Renard, K. G., Foster, G. R., Weesies, G. A., McCool, D. K., and Yoder, D. C.: Predicting Soil Erosion by Water: A Guide to Conservation Planning with the Revised Universal Soil Loss Equation (RUSLE), Handbook \#703. US Department of Agriculture, Washington, DC, 1997.

Richardson, C. W., Foster, G. R., and Wright, D. A.: Estimation of Erosion Index from Daily Rainfall Amount, T. ASAE, 26, 153160, 1983.

Rodrigo, F. S.: Changes in the probability of extreme daily precipitation observed from 1951 to 2002 in the Iberian Peninsula, Int. J. Climatol., 30, 1512-1525, 2010.

Rodrigo, F. S., Trigo, R. M.: Trends in daily rainfall in the Iberian Peninsula from 1951 to 2002, Int. J. Climatol., 27, 513-529, 2007.

Rodríguez-Puebla, C., Encinas, A. H., Nieto, S., and Garmendia, J.: Spatial and temporal patterns of annual precipitation variability over the Iberian Peninsula, Int. J. Climatol., 18, 229-316, 1998. 
Romero, R., Guijarro, J. A., Ramis, C., and Alonso, S.: A 30-year (1964-1993) daily rainfall data base for the Spanish Mediterranean regions: first exploratory study, Int. J. Climatol., 18, 541560,1998

Sauerborn, P., Klein, D. A., Botschek, J., and Skowronek, A.: Future rainfall erosivity from large scale climate models - methods and scenarios for a humid region, Geoderma, 93, 269-276, 1999.

Tramblay, Y., Badi, W., Driouech, F., El Adlouni, S., Neppel, L., and Servat, E.: Climate change impacts on extreme precipitation in Morocco, Global Planet. Change, 82-83, 104-114, 2012.

Vicente-Serrano, S. M., Beguería, S., López-Moreno, J. I., GarcíaVera, M. A., and Stepanek, P.:A complete daily rainfall database for north-east Spain: Reconstruction, quality control and homogeneity, Int. J. Climatol., 30, 1146-1163, 2009a.
Vicente-Serrano, S. M., Beguería, S., López-Moreno, J. I., El Kenawy, A., and Angulo-Martínez, M.: Daily atmospheric circulation events and extreme precipitation risk innortheast Spain: Role of the North Atlantic Oscillation, the WesternMediterranean Oscillation, and the Mediterranean Oscillation, J.Geophys. Res., 114, D08106, doi:10.1029/2008JD011492, 2009b.

Wischmeier, W. H. and Smith, D. D.: Predicting rainfall erosion losses: a guide to conservation planning, USDA Handbook 537, Washington, DC, 1978.

Wischmeier, W. H.: A rainfall erosion index for a universal soil-loss equation, Soil Sci. Soc. Am. Proc., 23, 246-249, 1959. 